\title{
FATORES QUE INFLUENCIAM O PROCESSO DE ENSINO- APRENDIZAGEM SOB A PERSPECTIVA DE ALUNOS DO CURSO DE CIÊNCIAS CONTÁBEIS: UMA ANÁLISE COMPARATIVA ENTRE INSTITUIÇÕES DE ENSINO SUPERIOR PÚBLICAS E PRIVADAS
}

\author{
Carmem Lúcia Nascimento da Silva, Universidade Federal de Campina Grande - UFCG \\ carmemluciands@gmail.com
}

Lúcia Silva Albuquerque de Melo, Universidade Federal de Campina Grande - UFCG

luciasalbuquerque@gmail.com

Islania A. de Lira Delfino, Universidade Federal de Campina Grande - UFCG

islania_adm@hotmail.com

\begin{abstract}
RESUMO
Esta pesquisa objetivou investigar os fatores que influenciam o processo de ensino-aprendizagem na percepção dos discentes do curso de ciências contábeis de três Instituições de Ensino Superior, sendo elas, Universidade Federal de Campina Grande - Campus Sousa, Universidade Estadual da Paraíba Campus Campina Grande e uma Instituição de Ensino Superior Privada. A pesquisa foi realizada através da aplicação de questionários, totalizando 205 respostas válidas. Os resultados mostraram, que as variáveis que se destacaram como mais influenciadoras no processo de ensino-aprendizagem na perspectiva dos alunos foram: a didática do professor, referente ao fator professor; o programa da disciplina bem planejado, referente ao fator assunto; Desejo de aprender o assunto, fator aluno; e com relação ao aspecto institucional da IES Federal, predominou a resposta de existência de auxiliares de ensino e de monitores, enquanto que, na Estadual e Privada, biblioteca equipada com um extenso acervo de livros e instalações adequadas. Com relação às atitudes negativas do professor, a falta de domínio do assunto a ser explanado foi a mais citada entre os estudantes. Através dos resultados apresentados, espera-se colaborar para que haja efetividade no processo de ensino-aprendizagem do curso de Ciências Contábeis.
\end{abstract}

PALAVRAS-CHAVE: Ciências Contábeis; Ensino Aprendizagem; Análise Comparativa

\section{FACTORS THAT INFLUENCE THE TEACHING-LEARNING PROCESS UNDER THE PERSPECTIVE OF STUDENTS IN THE COURSE OF ACCOUNTING SCIENCES: A COMPARATIVE ANALYSIS BETWEEN PUBLIC AND PRIVATE HIGHER EDUCATION INSTITUTIONS}

\begin{abstract}
This research aimed to investigate the factors that influence the teaching-learning process in the perception of the students of the accounting sciences course of three Higher Education Institutions, being the Federal University of Campina Grande - Campus Sousa, State University of Paraíba - Campina Grande Campus And a Private Higher Education Institution. The research was carried out through the application of questionnaires, totaling 205 valid answers. The results showed that the variables that stood out as most influential in
\end{abstract}


the teaching-learning process from the perspective of the students were: teacher didactics, referring to the teacher factor; The program of the discipline well planned, referring to the subject factor; Desire to learn the subject, student factor; And in relation to the institutional aspect of the Federal HEI, there was a predominant response to the existence of teaching aides and monitors, while in the State and Private schools, a library equipped with an extensive collection of books and adequate facilities. With regard to the negative attitudes of the teacher, the lack of mastery of the subject to be explained was the most cited among the students. Through the presented results, it is hoped to collaborate so that there is effectiveness in the teaching-learning process of the course of Accounting Sciences.

KEY WORDS: Accounting Sciences; Teaching Learning; Comparative Analysis

\title{
FACTORES QUE INFLUENCIAR EL PROCESO DE ENSEÑANZA-APRENDIZAJE BAJO LA PERSPECTIVA DE ALUMNOS DEL CURSO DE CIENCIAS CONTABLES: UN ANÁLISIS COMPARATIVO ENTRE INSTITUCIONES DE ENSEÑANZA SUPERIOR PÚBLICAS Y PRIVADAS
}

\begin{abstract}
RESUMEN
Esta investigación objetivó investigar los factores que influencian el proceso de enseñanzaaprendizaje en la percepción de los discentes del curso de ciencias contables de tres Instituciones de Enseñanza Superior, siendo ellas, Universidad Federal de Campina Grande Campus Sousa, Universidad Estadual de Paraíba - Campus Campina Grande Y una Institución de Enseñanza Superior Privada. La encuesta fue realizada a través de la aplicación de cuestionarios, totalizando 205 respuestas válidas. Los resultados mostraron que las variables que se destacaron como más influyentes en el proceso de enseñanzaaprendizaje en la perspectiva de los alumnos fueron: la didáctica del profesor, referente al factor profesor; El programa de la disciplina bien planificada, referente al factor asunto; Deseo de aprender el asunto, factor alumno; Y con relación al aspecto institucional de la IES Federal, predominó la respuesta de existencia de auxiliares de enseñanza y de monitores, mientras que en la Estatal y Privada, biblioteca equipada con un extenso acervo de libros e instalaciones adecuadas. Con respecto a las actitudes negativas del profesor, la falta de dominio del asunto a ser explicado fue la más citada entre los estudiantes. A través de los resultados presentados, se espera colaborar para que haya efectividad en el proceso de enseñanza-aprendizaje del curso de Ciencias Contables.
\end{abstract}

\section{PALABRAS CLAVE: Ciencias Contables; Enseñanza Aprendizaje; Análisis Comparativo}

\section{INTRODUÇÃO}

A esfera contábil vem se expandindo no Brasil desencadeando uma sequência de modificações nas últimas décadas, tanto no contexto econômico como social, na qual, parte da necessidade do próprio mercado, da percepção de como o ser humano se desenvolve e absorve o conhecimento. Assim há a necessidade de atribuir um novo sentido a contabilidade para atender as novas imposições profissionais e sociais (BECK, RAUSCH, 2012). 
Segundo Pavione, Avelino e Francisco (2016), a educação é a base para o desenvolvimento intelectual, ético e de habilidades de um indivíduo, em um processo de civilização e aprendizado. Na qual, quando acontece em ambientes como universidades e escolas, chama-se de ensino. Então, consequentemente, ensinar é a principal tarefa de uma Instituição de Ensino.

Beck e Rausch (2012) enfatizam o processo de ensino aprendizagem como idealizado e planejado para a evolução dos envolvidos: professor e aluno. E de acordo com a forma que acontece essa relação, a aprendizagem do aluno poderá ser mais ou menos facilitada e direcionada para uma ou outra vertente. Sendo assim, torna-se imprescindível a sapiência dos fatores que o influenciam.

Portanto, qualquer Instituição de Ensino Superior tem o dever de proporcionar aos estudantes um ensino de qualidade que possa bem prepara-los para o mercado de trabalho. É de sua responsabilidade a disseminação do conhecimento, a construção de pesquisadores e profissionais (PAVIONE, AVELINO, FRANCISCO, 2016). O docente é responsável por preparar futuros profissionais que atendam à demanda do mercado e da sociedade em relação a conhecimentos intelectuais, técnicos e morais. Para que os saberes sejam absorvidos pelos alunos é necessário que haja professores capacitados.

No entanto, Vendruscolo e Behar (2014) diz que o curso de ciências contábeis está evoluindo cientificamente, porém seu status indica condição de estágio semicientífico, no qual, para sua evolução será necessário pesquisar profundamente as teorias que lhe suportam, bem como dos seus modelos desenvolvidos. Outro problema seria a falta de bibliografia sobre metodologia para ensino superior em ciências contábeis que ajudem os professores com os obstáculos da docência.

É de se considerar que os alunos têm participação significativa no seu próprio desempenho, visto que só a qualidade do professor não basta. Tem que haver o interesse e compromisso do aluno em apreender os assuntos dentro e fora da sala de aula. Dessa forma, torna-se necessário saber os fatores que influenciam o desempenho dos alunos, para que melhorias possam ser implantadas no processo de ensino-aprendizagem.

Nesse contexto, surge a seguinte questão da pesquisa: Quais os fatores que influenciam o processo de ensino-aprendizagem na percepção dos discentes do curso de Ciências Contábeis?. Tendo como objetivo geral investigar os fatores que influenciam o 
processo de ensino-aprendizagem na percepção dos discentes do curso de ciências contábeis de uma IES Federal, uma IES Estadual e outra Privada do Estado da Paraíba.

Diversos estudos brasileiros vêm investigando aspectos relacionados a temática ensino-aprendizagem, bem como os fatores que influenciam o processo de ensinoaprendizagem, tais como, Pavione, Avelino e Francisco (2016) que identificaram os fatores que influenciam o processo de ensino aprendizagem de uma Instituição de Ensino Superior”, e Beck e Rausch (2012) que tiveram por objetivo "verificar a percepção de discentes do curso de Ciências Contábeis de uma IES em relação aos fatores que influenciam o processo de ensino-aprendizagem".

Apesar de existir pesquisas amplas sobre a temática ensino-aprendizagem em Contabilidade, na perspectiva dos estudantes ainda existe campo de pesquisa, por isso sua relevância. Na visão de Pavione, Avelino e Francisco (2016) estudos em contabilidade sobre o processo de ensino-aprendizagem é um tema de extrema relevância no meio acadêmico, devendo abranger todos os atores participantes desse processo (aluno, professor e instituição), mas, principalmente, o aluno e o professor. Como diferencial a presente pesquisa se propõe a investigar os fatores que influenciam o processo de ensino-aprendizagem na perspectiva dos alunos do curso de Ciências Contábeis comparando três Instituições de Ensino Superior: uma Estadual, uma Federal e outra Privada.

\section{REVISÃO DA LITERATURA}

\subsection{O Processo de Ensino-Aprendizagem}

O ensino-aprendizagem é um dos processos mais fascinantes e complexos do pensamento humano. Conforme Miranda, Miranda e Costa (2011), corresponde a um processo de diálogo entre os elementos que formam o ensino em uma IES, que são: o aluno, o professor e a própria Instituição de Ensino Superior por meio de suas instalações. O aluno recebe as informações transmitidas pelo professor, usufruidor dos recursos proporcionados pela Instituição e ainda provido de propriedades psicológicas e emocionais intrínsecas a ele próprio. O docente tem a maior relevância nesse processo; ele é o atenuador e facilitador na relação do aluno com a IES e os assuntos do curso. E, finalmente a IES, que é o ambiente interno, que proporciona ao discente, recursos de auxílio para a efetivação do processo. 
Nesse processo de ensino e aprendizagem, o aluno toma um lugar de suma relevância, uma vez que as estratégias pedagógicas são destinadas a ele. É baseado em seu conhecimento, capacidade e desenvolvimento, que as atividades lhes serão ofertadas. O grande desafio do educador é a aptidão de trabalhar em um nível acima da capacidade do aluno (BRAGA, 2012).

Em relação à Contabilidade, era utilizado no processo de ensino métodos no qual o aluno era sujeito passivo. Mas hoje repensaram esses métodos, pois os futuros bacharéis em Ciências Contábeis precisam de um vasto conhecimento, tendo uma formação para atuar em diversas áreas, discurso crítico e capacidade de julgamento e difusão de opiniões (SANTOS, et al. 2012).

Souza et al. (2016) alerta que nesse processo, fatores como: as condições de trabalho dos professores, a estrutura da instituição de ensino, as condições sociais dos alunos e seus recursos podem interferir nos resultados dos discentes, além das mudanças sociais e das novas exigências impostas, com o intuito de melhor preparar o aluno para o mercado. Nas últimas décadas, no cenário contábil têm ocorrido muitas mudanças para atender as novas exigências profissionais e sociais.

Com relação à influência que o aluno exerce no processo ensino aprendizagem, notase que, por consequência do processo de democratização do ensino, diferentes grupos sociais conseguiram acesso às escolas. Atualmente, os alunos constituem um grupo heterogêneo com motivações, heranças culturais, interesses e religiões diferentes. Nesse sentido, algumas características do aluno podem influenciar o processo de ensino-aprendizagem, como: capacidade de manter interação entre docentes e colegas; motivação pessoal para apreender o que está sendo explanado, e o costume de estudar fora da sala de aula e de tentar encontrar em outras fontes o conhecimento almejado (PAVIONE, AVELINO, FRANCISCO, 2016).

Beck e Rausch (2012) enfatizam como pontos fundamentais na dimensão aluno, os motivos pessoais do estudante; o relacionamento com o docente; os conhecimentos prévios sobre o conteúdo ministrado e a atitude com a disciplina. Quanto as atitudes do aluno que podem ser um obstáculo no processo de ensino-aprendizagem, os próprios envolvidos apontaram os seguintes fatores como aspectos principais: pouca dedicação extracurricular; escassez de interesse, desprezo e pouco empenho; conversas paralelas em excesso; não responder as atividades feitas em sala, e poucas indagações quanto aos conteúdos estudados. 
Atualmente, o docente de Ciências Contábeis deve combinar as habilidades e os conhecimentos da profissão aos conhecimentos pedagógicos e didáticos. Além da imposição da titulação, é imprescindível que o professor aprenda a combinar os conhecimentos práticos e teóricos, tornando o teórico tão significativo e importante, quanto o prático prazeroso e inteligível (RODRIGUES, PASSOS, 2015).

Diante disso, foi tomado como base os estudos de Bordenave e Pereira (2012), em que os perfis do professor dão auxílio a sua conduta em circunstâncias de ensino e aprendizagem, especialmente em sala de aula:

A competência do professor é adquirida aos poucos no cotidiano do relacionamento que desenvolve com o corpo discente. Conciliar seu compromisso com a finalidade educativa, com suas competências e com o sentido que o discente conquista quando participa ativamente do processo de ensino-aprendizagem é o papel fundamental a ser executado pelo docente universitário de qualquer IES (GUIMARÃES, 2014).

\section{METODOLOGIA}

Considerando o objetivo proposto para este estudo, que visa investigar os fatores que influenciam o processo de ensino-aprendizagem na percepção dos discentes do curso de ciências contábeis, a pesquisa é caracterizada como descritiva. Quanto aos meios, caracterizase como uma pesquisa bibliográfica, pois foi desenvolvida a partir de artigos científicos, revistas e livros. Também pode ser caracterizada como pesquisa de campo já que utilizará questionários desenvolvidos pelos pesquisadores como instrumento para coleta de dados. Quanto ao problema refere-se a uma pesquisa qualitativa e quantitativa.

O universo de pesquisa é composto por 205 alunos dos $3^{\circ}$ período, $5^{\circ}$ período, $7^{\circ}$ período e do último período do curso de Ciências Contábeis de três Instituições de Ensino Superiores, sendo elas: Universidade Federal de Campina Grande - Campus Sousa (UFCG), Universidade Estadual da Paraíba - Campus Campina Grande (UEPB) e uma Instituição de Ensino Superior Privada, cada qual com 72, 96 e 37 respondentes, respectivamente.

Optou-se pela escolha desses estudantes, pois, na UFCG a entrada de uma nova turma se dá anualmente, e não, semestralmente. Dessa forma foram selecionados os mesmos períodos nas demais Instituições. Além disso, acredita-se também que todas as experiências 
vividas por esses alunos no ensino superior são mais engrandecedoras em relação àquelas dos estudantes do primeiro ano.

A amostra de dados analisada vale como uma amostragem não probabilística por conveniência. Dessa forma, os resultados descobertos resumem-se à amostra analisada, e consequentemente estando impossibilitado de realizar inferências para a população. Nesse caso, foram analisados os alunos do curso de Ciências Contábeis de três universidades localizadas no Estado da Paraíba.

A coleta de dados deu-se por meio de um questionário elaborado pelos pesquisadores, na qual foi aplicado no período de duas semanas entre os meses de fevereiro e março de 2017.

Foram adotadas duas maneiras de aplicação: A primeira é feita pessoalmente, em sala de aula, com a ajuda de docentes através de formulário impresso; A segunda maneira, através de e-mail em formato online.

O questionário foi fracionado em cinco partes, como se consegue perceber no Quadro 2.

Quadro 1. Descrição do Questionário por partes

\begin{tabular}{|c|l|}
\hline Parte & \multicolumn{1}{|c|}{ Objetivo } \\
\hline I & $\begin{array}{l}\text { Identificar os fatores que influenciam o processo de ensino aprendizagem de } \\
\text { acordo com o que os participantes da pesquisa opinaram. }\end{array}$ \\
\hline II & $\begin{array}{l}\text { Identificar quais as atitudes dos alunos e professores, na percepção do aluno, } \\
\text { que influenciam negativamente o processo de aprendizagem. }\end{array}$ \\
\hline III & $\begin{array}{l}\text { Identificar quais os tipos de professores, na percepção dos alunos, que } \\
\text { proporcionem um melhor aprendizado. }\end{array}$ \\
\hline
\end{tabular}

Fonte: Adaptado de Pavione, Avelino, Francisco (2016).

Com referência ao retorno dos questionários foram obtidas 205 respostas classificadas para análise, sendo 72 da UFCG, 96 da UEPB e 37 da IES Privada.

\section{ANÁLISE DOS DADOS}

A amostra analisada nesse estudo é formada por 205 observações no total, sendo que na UFCG são 72 respondentes, formada por $47,22 \%$ do sexo feminino e $52,78 \%$ do sexo masculino. Já na UEPB, formada por 96 respondentes, 47,92\% é do sexo feminino e 52,08\%, masculino, que se torna parecido com relação á Instituição Federal. Enquanto na IES Privada, é ao contrário: o sexo feminino constitui $35,14 \%$ dos respondentes pesquisados, e masculino, $62,16 \%$. 


\subsection{Fatores que influenciam o processo de Ensino-aprendizagem}

Nesse tópico, foram considerados como aspectos que influenciam o processo de ensino aprendizagem os fatores: Professor, Aluno, Assunto e Instituição. Dessa forma, foram questionados aos respondentes, variáveis sobre cada fator citado. Na tabela 1, será representado o fator Professor.

Tabela 1. Fatores do Processo de Ensino-aprendizagem - Dimensão Professor

\begin{tabular}{|c|c|c|c|c|c|c|c|}
\hline \multirow{2}{*}{$\begin{array}{l}\text { Fatores do Processo de Ensino- } \\
\text { Aprendizagem - Dimensão } \\
\text { Professor }\end{array}$} & \multicolumn{2}{|c|}{ IES Federal } & \multicolumn{2}{|c|}{ IES Estadual } & \multicolumn{2}{|c|}{ IES Privada } & \multirow[b]{2}{*}{ Total } \\
\hline & S & $\mathrm{N}$ & S & $\mathrm{N}$ & S & $\mathrm{N}$ & \\
\hline $\begin{array}{l}\text { Didática do professor (forma como } \\
\text { o professor conduz a aula, interage } \\
\text { com os alunos e proporciona um } \\
\text { ambiente de aprendizado). }\end{array}$ & $61,11 \%$ & $38,89 \%$ & $90,63 \%$ & $9,37 \%$ & $81,08 \%$ & $18,92 \%$ & $100 \%$ \\
\hline $\begin{array}{l}\text { Nível de exigência em provas } \\
\text { condizente com o que foi ensinado } \\
\text { em aula. }\end{array}$ & $11,11 \%$ & $88,89 \%$ & $16,67 \%$ & $83,33 \%$ & $8,11 \%$ & $91,89 \%$ & $100 \%$ \\
\hline $\begin{array}{l}\text { Uso de linguagem adequada em sala } \\
\text { de aula, com ausência de } \\
\text { comunicação que implique ironia e } \\
\text { sarcasmo por parte do professor } \\
\text { para o domínio do ambiente. }\end{array}$ & $22,22 \%$ & $77,78 \%$ & $8,33 \%$ & $91,67 \%$ & $16,22 \%$ & $83,78 \%$ & $100 \%$ \\
\hline $\begin{array}{l}\text { Atitudes de subordinação para com } \\
\text { a turma (redução de exercícios, } \\
\text { facilidade nas provas, vista grossa a } \\
\text { faltas e tolerância a indisciplina). }\end{array}$ & $9,72 \%$ & $90,28 \%$ & $3,12 \%$ & $96,88 \%$ & $2,70 \%$ & $97,30 \%$ & $100 \%$ \\
\hline Vocação do professor para dar aula. & $13,89 \%$ & $86,11 \%$ & $21,87 \%$ & $78,13 \%$ & $8,11 \%$ & $91,89 \%$ & $100 \%$ \\
\hline $\begin{array}{l}\text { Domínio e gosto pela disciplina } \\
\text { lecionada. }\end{array}$ & $19,44 \%$ & $80,56 \%$ & $28,12 \%$ & $71,88 \%$ & $18,92 \%$ & $81,08 \%$ & $100 \%$ \\
\hline $\begin{array}{l}\text { Ter um bom relacionamento com o } \\
\text { aluno (procurar entender seus } \\
\text { hábitos e costumes, interesse em } \\
\text { conhecer os alunos, ouvi-los e } \\
\text { compreendê-los). }\end{array}$ & $11,11 \%$ & $88,89 \%$ & $22,92 \%$ & $77,08 \%$ & $10,82 \%$ & $89,18 \%$ & $100 \%$ \\
\hline
\end{tabular}

Fonte: Elaborado pelos autores (2017).

$\mathrm{Na}$ análise desse fator, os respondentes indicaram em sua maioria como fator influenciador do ensino aprendizagem em relação às atitudes do professor, referente à UFCG, com $61,11 \%$, a "Didática do professor (forma como o professor conduz a aula, interage com os alunos e proporciona um ambiente de aprendizado)", seguido de "Uso de linguagem adequada em sala de aula, com ausência de comunicação que implique ironia e sarcasmo por parte do professor para o domínio do ambiente" com 22,22\% das indicações. 
Na UEPB não foi diferente. 90,63\% dos alunos citaram "Didática do professor" como fator influenciador, em seguida, destacou-se "Domínio e gosto pela disciplina lecionada" com $28,12 \%$.

Enquanto que na IES Privada, a "Didática do professor" foi o quesito mais citado pelos respondentes, com 81,08\%, e "Domínio e gosto pela disciplina lecionada" com 18,92\%.

Dessa forma, pode-se observar que por unanimidade, a didática do professor foi o fator mais importante apontado pelos alunos, como influenciador no processo de ensinoaprendizagem. Da mesma maneira, as "Atitudes de subordinação para com a turma (redução de exercícios, facilidade nas provas, vista grossa a faltas e tolerância a indisciplina)" foram as variáveis menos apontadas nesse processo, mas, não quer dizer que seja menos importante, apenas afeta numa magnitude menor.

O próximo fator analisado foi o Assunto tratado em sala de aula, que se pode observar na tabela 2 .

Tabela 2. Fatores do Processo de Ensino-Aprendizagem - Dimensão Assunto

\begin{tabular}{|c|c|c|c|c|c|c|c|}
\hline \multirow{2}{*}{$\begin{array}{l}\text { Fatores do Processo de Ensino- } \\
\text { Aprendizagem }- \text { Dimensão } \\
\text { Assunto }\end{array}$} & \multicolumn{2}{|c|}{ IES Federal } & \multicolumn{2}{|c|}{ IES Estadual } & \multicolumn{2}{|c|}{ IES Privada } & \multirow[b]{2}{*}{ Total } \\
\hline & S & $\mathrm{N}$ & $\mathrm{S}$ & $\mathrm{N}$ & $\mathrm{S}$ & $\mathrm{N}$ & \\
\hline \begin{tabular}{|llll}
$\begin{array}{l}\text { Estrutura } \\
\text { disciplina }\end{array}$ & do conteúdo da \\
\end{tabular} & $19,44 \%$ & $80,56 \%$ & $28,13 \%$ & $71,87 \%$ & $35,13 \%$ & $64,87 \%$ & $100 \%$ \\
\hline $\begin{array}{l}\text { Interação entre os programas } \\
\text { de diversas disciplinas }\end{array}$ & $23,61 \%$ & $\%$ & $19,80 \%$ & $80,20 \%$ & $10,81 \%$ & $89,19 \%$ & $100 \%$ \\
\hline 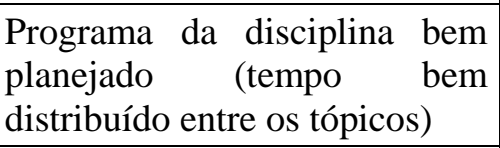 & 43,0 & & $1 \%$ & $\%$ & $5 \%$ & 48 & $100 \%$ \\
\hline $\begin{array}{l}\text { Afinidade dos programas co } \\
\text { os fatos do dia a dia }\end{array}$ & $26,39 \%$ & $73,61 \%$ & $45,83 \%$ & $54,17 \%$ & $13,51 \%$ & $86,49 \%$ & $100 \%$ \\
\hline
\end{tabular}

Fonte: Elaborado pelos autores (2017).

Na tabela 2 verifica-se que a variável "Programa da disciplina bem planejado, foi a que recebeu mais indicações entre as três Instituições de Ensino Superior analisadas: UFCG 43,06\%; UEPB - 51,04\%; e IES Privada - 51,35\%. As variáveis menos mencionadas nesse fator foram: UFCG - Estrutura do conteúdo da disciplina; UEPB e IES Privada - Interação entre os programas de diversas disciplinas.

A tabela 3 representará os fatores influenciadores do processo de ensinoaprendizagem, com relação ao fator aluno:

Tabela 3. Fatores do Processo de Ensino-Aprendizagem - Dimensão Aluno

\begin{tabular}{l|l|l|l|l}
\hline Fatores do Processo de & IES Federal & IES Estadual & IES Privada & Total \\
\hline
\end{tabular}




\begin{tabular}{l|l|l|l|l|l|l|l}
\hline $\begin{array}{l}\text { Ensino-Aprendizagem - } \\
\text { Dimensão Aluno }\end{array}$ & $\mathrm{S}$ & $\mathrm{N}$ & $\mathrm{S}$ & $\mathrm{N}$ & $\mathrm{S}$ & $\mathrm{N}$ & \\
\hline $\begin{array}{l}\text { Número adequado de } \\
\text { alunos em sala de aula e } \\
\text { um público homogêneo }\end{array}$ & $4,17 \%$ & $95,83 \%$ & $10,42 \%$ & $89,58 \%$ & $8,11 \%$ & $91,89 \%$ & $100 \%$ \\
\hline $\begin{array}{l}\text { Desejo de aprender o } \\
\text { assunto (motivação } \\
\text { pessoal com a disciplina) }\end{array}$ & $45,83 \%$ & $54,17 \%$ & $60,42 \%$ & $39,58 \%$ & $56,76 \%$ & $43,24 \%$ & $100 \%$ \\
\hline $\begin{array}{l}\text { Existência de } \\
\text { conhecimentos prévios } \\
\text { que permitirão aprender } \\
\text { melhor o assunto para as }\end{array}$ & $22,22 \%$ & $77,78 \%$ & $19,79 \%$ & $80,21 \%$ & $24,32 \%$ & $75,68 \%$ & $100 \%$ \\
\hline $\begin{array}{l}\text { Estar preparado para } \\
\text { responsabilidades de um } \\
\text { curso } \\
\text { (maturidade) }\end{array}$ & $15,28 \%$ & $84,72 \%$ & $22,92 \%$ & $77,08 \%$ & $5,40 \%$ & $94,60 \%$ & $100 \%$ \\
\hline \begin{tabular}{l} 
Ter o hábito de estudar \\
\hline $\begin{array}{l}\text { Boa relação com o professor } \\
\text { (respeitar e saber dialogar } \\
\text { com ele) }\end{array}$
\end{tabular} 220,$83 \%$ & $79,17 \%$ & $27,08 \%$ & $72,92 \%$ & $13,51 \%$ & $86,49 \%$ & $100 \%$ \\
\hline
\end{tabular}

Fonte: Elaborado pelos autores (2017).

Nesse tópico, percebe-se que a maior parte dos respondentes, nas três instituições, escolheram a variável "Desejo de aprender o assunto" como principal fator influenciador no ensino aprendizagem, ou seja, a motivação para aprender a disciplina é o aspecto essencial para o aluno. Os resultados apontaram maioria de 45,83\% na UFCG, $60,42 \%$ na UEPB e $56,75 \%$ na IES Privada.

Avaliando no geral, os estudantes concordaram que todas as variáveis que tem origem de seu desejo, atitudes e relações influenciam o processo de ensino-aprendizagem. E finalmente, a tabela 4 irá representar o resultado da análise das variáveis do fator Institucional, que se refere ao suporte que a Instituição deve dar ao aluno e professor.

Tabela 4. Fatores do Processo de Ensino-Aprendizagem - Dimensão Institucional

\begin{tabular}{l|c|c|c|c|c|c|c}
\hline $\begin{array}{l}\text { Fatores do Processo de Ensino- } \\
\text { Aprendizagem - Dimensão }\end{array}$ & \multicolumn{2}{|c|}{ IES Federal } & \multicolumn{2}{|c|}{ IES Estadual } & \multicolumn{2}{|c|}{ IES Privada } & \multirow{2}{*}{ Total } \\
\cline { 2 - 8 } Institucional & $\mathrm{S}$ & $\mathrm{N}$ & $\mathrm{S}$ & $\mathrm{N}$ & $\mathrm{S}$ & $\mathrm{N}$ & \\
\hline $\begin{array}{l}\text { Existência de auxiliares de } \\
\text { ensino e de monitores. }\end{array}$ & $30,56 \%$ & $69,44 \%$ & $26,04 \%$ & $73,96 \%$ & $13,51 \%$ & $86,49 \%$ & $100 \%$ \\
\hline $\begin{array}{l}\text { Assistência para os professores } \\
\text { na elaboração do material } \\
\text { didático e na sua orientação } \\
\text { pedagógica. }\end{array}$ & $27,78 \%$ & $72,22 \%$ & $33,33 \%$ & $66,67 \%$ & $35,13 \%$ & $64,87 \%$ & $100 \%$ \\
$\begin{array}{l}\text { Assistência e orientação } \\
\text { psicológica e vocacional para } \\
\text { os estudantes. }\end{array}$ & $13,89 \%$ & $86,11 \%$ & $14,58 \%$ & $85,42 \%$ & $8,11 \%$ & $91,89 \%$ & $100 \%$ \\
\end{tabular}


Salas de aula arejadas e equipadas com recursos audiovisuais.

Biblioteca equipada com um extenso acervo de livros instalações adequadas.

\begin{tabular}{|l|l|l|l|l|l|l}
$20,83 \%$ & $79,17 \%$ & $35,42 \%$ & $64,58 \%$ & $32,43 \%$ & $67,57 \%$ & $100 \%$ \\
\hline $29,17 \%$ & $70,83 \%$ & $59,38 \%$ & $40,62 \%$ & $43,24 \%$ & $56,76 \%$ & $100 \%$ \\
\hline
\end{tabular}

Fonte: Elaborado pelos autores (2017).

As variáveis da dimensão institucional receberam médias similares, mostrando que os alunos consideram o fator em análise de grande relevância para sua aprendizagem, destacando-se as variáveis "Existência de auxiliares de ensino e de monitores" com 30,56\%, "Biblioteca equipada com um extenso acervo de livros e instalações adequadas" com 29,17\% e "Assistência para os professores na elaboração do material didático e na sua orientação pedagógica" com 27,78\% na UFCG; Já na UEPB e IES Privada, as variáveis mais citadas foram: "Biblioteca equipada com um extenso acervo de livros e instalações adequadas" com $59,38 \%$ e 43,24\%; "Salas de aula arejadas e equipadas com recursos audiovisuais" com 35,42\% e 32,43\%; e "Assistência para os professores na elaboração do material didático e na sua orientação pedagógica" com 33,33\% e 35,13\%, respectivamente.

Dessa forma, pode-se observar que os estudantes mostram grande importância quando se refere a ter uma boa base para obter suas informações necessárias para concluir o curso com uma bagagem de conhecimentos, e a melhor forma é tendo uma biblioteca equipada, além de instalações adequadas.

No geral, todas as variáveis foram relevantes, pois, assim como os alunos, os professores também precisam de auxílio e sala de aulas equipadas para que o processo de ensino e aprendizagem dê certo.

\subsection{Atitudes que influenciam Negativamente no Processo de Ensino Aprendizagem}

Com o levantamento do resultado das respostas dos estudantes participantes, foi possível compreender quais atitudes dos próprios alunos e dos professores que mais influência de forma negativa o processo de ensino-aprendizagem no curso de ciências contábeis, estão representadas nas tabelas abaixo.

Tabela 5. Atitudes do Aluno

\begin{tabular}{|c|c|c|c|c|c|c|c|}
\hline \multirow{2}{*}{ Atitudes Aluno } & \multicolumn{2}{|c|}{ IES Federal } & \multicolumn{2}{|c|}{ IES Estadual } & \multicolumn{2}{|c|}{ IES Privada } & \multirow{2}{*}{ Total } \\
\hline & $S$ & $\mathrm{~N}$ & S & $\mathrm{N}$ & $S$ & $\mathrm{~N}$ & \\
\hline Falta de interesse & $29,17 \%$ & $70,83 \%$ & $44,79 \%$ & $55,21 \%$ & $35,14 \%$ & $64,86 \%$ & $100 \%$ \\
\hline Conversas paralelas em & $29,17 \%$ & $70,83 \%$ & $31,25 \%$ & $68,75 \%$ & $48,65 \%$ & $51,35 \%$ & $100 \%$ \\
\hline
\end{tabular}




\begin{tabular}{l|l|l|l|l|l|l|l}
\hline excesso & & & & & & & \\
\hline $\begin{array}{l}\text { Falta de dedicação fora } \\
\text { da sala de aula }\end{array}$ & $48,61 \%$ & $51,39 \%$ & $50 \%$ & $50 \%$ & $35,14 \%$ & $64,86 \%$ & $100 \%$ \\
\hline $\begin{array}{l}\text { Não desenvolver as } \\
\text { atividades propostas pelo } \\
\text { professor }\end{array}$ & $16,67 \%$ & $83,33 \%$ & $30,21 \%$ & $69,79 \%$ & $5,41 \%$ & $94,59 \%$ & $100 \%$ \\
\hline
\end{tabular}

Fonte: Elaborado pelos autores (2017).

Comparando as três instituições, verifica-se que entre a UFCG e a UEPB, que "A falta de dedicação fora da sala de aula" foi considerada a atitude negativa de maior peso no processo de ensino-aprendizagem, com um percentual de $48,61 \%$ e $50 \%$, respectivamente. Seguida de "Conversas paralelas" com um percentual de 29,17\% - UFCG, e 31,25\% - UEPB; e "falta de interesse" com 29,17\% - UFCG e 44,79\% - UEPB.

Nos resultados dos alunos da rede privada, a principal atitude negativa foram as "Conversas paralelas em excesso" com percentual de 48,65\%, seguida de "falta de interesse" e "falta de dedicação fora da sala de aula" com 35,14\% nas duas variáveis.

Na tabela 6, apresentam os resultados na percepção dos alunos, quais as atitudes negativas do professor em sala que pode atrapalhar no processo de ensino-aprendizagem.

Tabela 6. Atitudes do Professor

\begin{tabular}{l|l|l|l|l|l|l|l}
\hline Atitudes Professor & \multicolumn{2}{|l|}{ IES Federal } & \multicolumn{2}{l|}{ IES Estadual } & \multicolumn{2}{l|}{ IES Privada } & Total \\
\cline { 2 - 8 } & $\mathrm{S}$ & $\mathrm{N}$ & $\mathrm{S}$ & $\mathrm{N}$ & $\mathrm{S}$ & $\mathrm{N}$ & \\
\hline $\begin{array}{l}\text { Professor que não se } \\
\text { propõe a sanar as } \\
\text { dúvidas dos alunos }\end{array}$ & $20,73 \%$ & $79,17 \%$ & $51,04 \%$ & $48,96 \%$ & $29,73 \%$ & $70,27 \%$ & $100 \%$ \\
\hline $\begin{array}{l}\text { Impontualidade e falta } \\
\text { de motivação do } \\
\text { professor }\end{array}$ & $22,22 \%$ & $77,78 \%$ & $35,42 \%$ & $64,58 \%$ & $16,22 \%$ & $83,78 \%$ & $100 \%$ \\
\hline $\begin{array}{l}\text { Falta de domínio do } \\
\text { assunto a ser explanado }\end{array}$ & $66,67 \%$ & $33,33 \%$ & $65,63 \%$ & $34,37 \%$ & $70,27 \%$ & $29,73 \%$ & $100 \%$ \\
\hline $\begin{array}{l}\text { Excesso de aulas } \\
\text { expositivas }\end{array}$ & $13,89 \%$ & $86,11 \%$ & $16,67 \%$ & $83,33 \%$ & $5,40 \%$ & $94,60 \%$ & $100 \%$ \\
\hline
\end{tabular}

Fonte: Elaborado pelos autores (2017).

Das atitudes listadas, a "Falta de domínio do assunto a ser explanado" foi a mais pontuada por os alunos das três instituições, com percentual de 66,67\% na UFCG, $65,63 \%$ na UEPB e 70,27\% na IES Privada. E a menos pontuada, "Excesso de aulas expositivas", com apenas $13,89 \%, 16,67 \%$ e $5,4 \%$, respectivamente.

O gráfico abaixo representa o percentual de distribuição referente aos perfis dos professores na percepção dos estudantes de cada IES analisada.

Gráfico 1. Tipo de Professor Predominante 


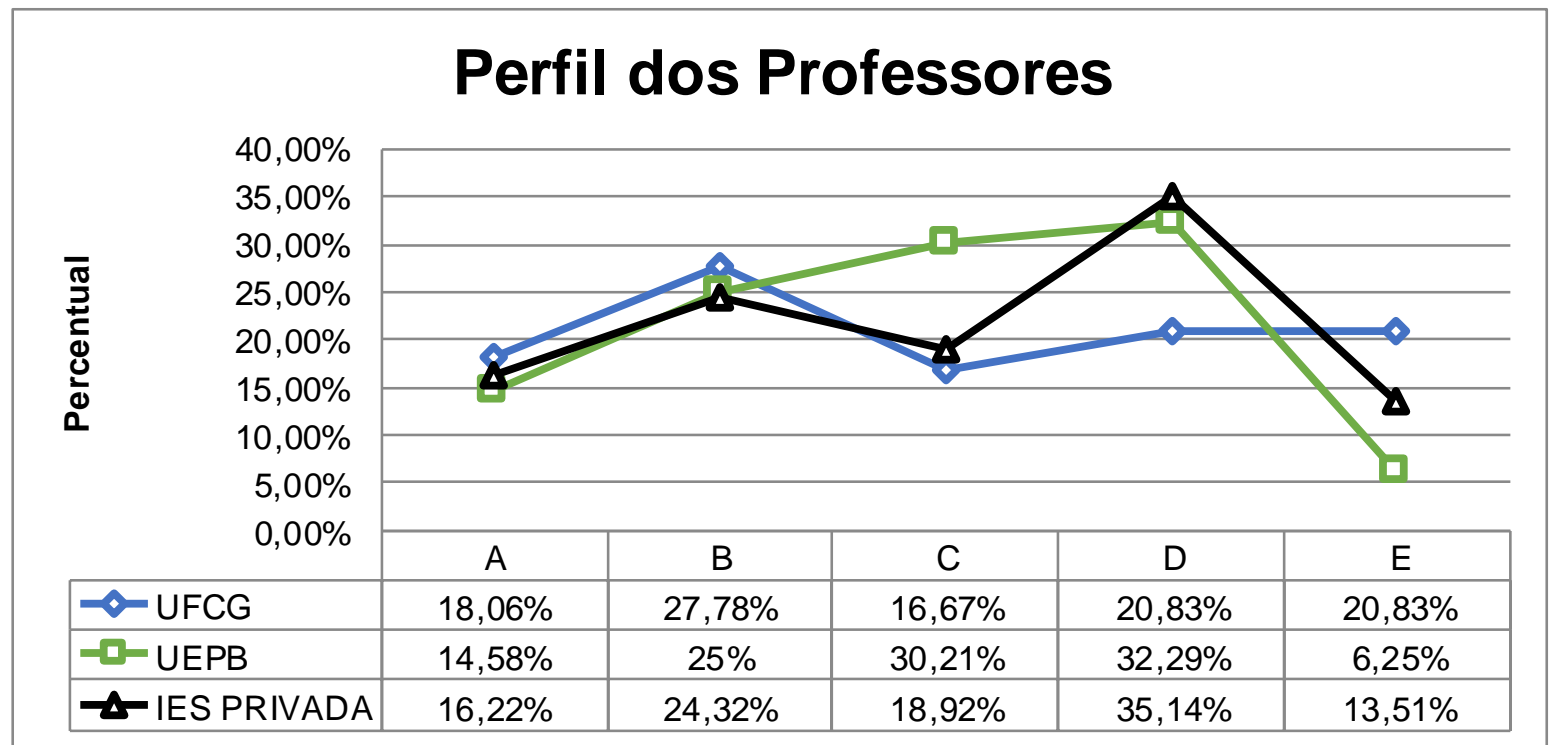

Fonte: Elaborado pelos autores (2017).

Legenda: A - Instrutor; B - O professor que se concentra no conteúdo; C - O professor que se concentra no processo de instrução; D - O professor que se concentra no intelecto do aluno; E - O professor que se concentra na pessoa total.

Com relação a UFCG, observa-se que o perfil escolhido pela maioria dos estudantes foi o perfil $\mathrm{B}$, com percentual de $27,78 \%$ das indicações: o professor que se concentra no conteúdo. Seguido de D (O professor que se concentra no intelecto do aluno) e E (O professor que se concentra na pessoa total), que obtiveram o mesmo percentual $-20,83 \%$.

$\mathrm{Na}$ percepção dos respondentes da UEPB, o perfil do professor que predomina no curso de Ciências Contábeis foi o perfil D, o professor que se concentra no intelecto do aluno, com 32,29\% das indicações. Seguido do C, o professor que se concentra no processo de instrução, com 30,21\%.

Enquanto que na IES Privada o perfil do professor que mais predomina indicado pelos alunos analisados foram o D, o professor que se concentra no intelecto do aluno, com percentual de $35,14 \%$. Seguido do B, O professor que se concentra no conteúdo, com 24,32\% das indicações. Os professores A e E, que equivalem no questionário ao "instrutor" ou professor de autômatos e o professor que se concentra na pessoa total, receberam as menores indicações, com $16,22 \%$ e $13,51 \%$, respectivamente.

De acordo com a pesquisa de Pavione, Avelino e Francisco (2016) na percepção dos estudantes analisados, o perfil do professor que predomina no curso de Ciências Contábeis seriam o perfil $\mathrm{C}$ - $\mathrm{O}$ professor que se concentra no processo de instrução, e, o B - O professor que se concentra no conteúdo, fortalecendo os resultados encontrados. 


\section{CONSIDERAÇÕES FIMAIS}

Esta pesquisa objetivou investigar os fatores que influenciam o processo de ensinoaprendizagem na percepção dos discentes do curso de ciências contábeis de três Instituições de Ensino Superior, sendo elas, Universidade Federal de Campina Grande - Campus Sousa, Universidade Estadual da Paraíba - Campus Campina Grande e uma Instituição de Ensino Superior Privada.

Averiguou-se dentre as variáveis que mais interferem no processo de ensino e aprendizagem dos discentes das Instituições de Ensino Superior são: a didática do professor; o programa da disciplina bem planejado; Desejo de aprender o assunto e com relação ao aspecto institucional da UFCG, predominou a resposta de existência de auxiliares de ensino e de monitores, enquanto que, na UEPB e na IES Privada, biblioteca equipada com um extenso acervo de livros e instalações adequadas.

Quanto ao perfil do professor predominante no curso de Ciências Contábeis, na percepção dos respondentes da UFCG é o perfil $\mathrm{B}$, ou seja: O professor que se concentra no conteúdo. Na percepção dos respondentes da UEPB e IES Privada, é o perfil D: O professor que se concentra no intelecto do aluno.

Os resultados encontrados corroboram com os resultados de Pavione, Avelino e Francisco (2016. Estão de acordo também com o estudo de Beck e Rausch (2012), em que os respondentes acreditam que a profissão os permite atuar em diferentes áreas ou segmentos da empresa. Ainda de acordo com Pavione, Avelino e Francisco (2016), os fatores que influenciam o processo de ensino-aprendizagem com relação ao fator professor é a sua didática ou forma como conduz à aula, interação com os alunos, proporcionando um ambiente de aprendizado. Além disso, o programa de disciplina bem planejado é um dos fatores mais importantes com relação ao assunto tratado em sala de aula, e, que o desejo de aprender o assunto é o fator motivacional do aluno.

Através dos resultados adquiridos, permitiu-se alcançar o objetivo proposto da pesquisa de investigar os fatores que influenciam o processo de ensino-aprendizagem na percepção de alunos do curso de Ciências Contábeis, comparando as Instituições de Ensino Superior UFCG, UEPB e a IES Privada, intensificando aspectos apresentados por outros autores. 
A pesquisa limitou-se em estudar o curso de Ciências Contábeis. Propõe-se para novas pesquisas mudar a direção da amostra, aplicando os questionários e comparando com outros cursos.

\section{REFERÊNCIAS}

BECK, Franciele. RAUSCH, Rita Buzzi. Fatores que influenciam o processo ensinoaprendizagem na percepção de discentes do curso de ciências contábeis. XII Congresso Usp. 2012.

BORDENAVE, J. D. \& Pereira, A. M. (2012). Estratégias de Ensino-Aprendizagem. 32. Ed. Petrópolis: Vozes.

BRAGA, E. M. Os elementos do processo de ensino-aprendizagem: Da sala de aula à educação mediada pelas tecnologias digitais da informação e da comunicação (TDICs).

Revista Vozes dos Vales: Publicações Acadêmicas. UFVJM, Minas Gerais, Brasil. № 02 Ano I - 10/2012. Disponível em: <http://site.ufvjm.edu.br/revistamultidisciplinar/files. Acesso em: 22 de fev. 2017.

GUIMARÃES, Jairo de Carvalho. Competências do Professor Universitário: A Prática Como Itinerário Para a Aprendizagem Ativa do Aluno e Para a Formação Continuada do Docente. XXXVIII Encontro da Anpad. Rio de Janeiro. Setembro de 2014.

MIRANDA, Gilberto José. NOVA, Silvia Pereira de Castro Casa. CORNACCHIONE JUNIOR, Edgard Bruno. Os Saberes dos Professores-Referência no Ensino de Contabilidade. R. Cont. Fin. - USP, São Paulo, v. 23, n. 59, p. 142-153, maio/jun./jul./ago. 2012.

MIRANDA, Raissa Alvares de Matos. MIRANDA, Claudio de Souza. COSTA, Glaucia Ferreira Machado. Estratégias de Ensino e Estilos de Aprendizagem: Um experimento no processo Ensino-Aprendizagem na Disciplina de Contabilidade Introdutória. III Encontro de Ensino e pesquisa em Administração e Contabilidade. João Pessoa, Paraíba. Novembro de 2011. Disponível em: <http://www.anpad.org.br/admin/pdf/EnEPQ304.pdf>. Acesso em: 22 de fev. 2017.

ORO, Ieda Margarete. SANTANA, Andre Gobette. RAUSCH, Rita Buzzi. Os Saberes do "Bom Professor" de Ciências Contábeis na Compreensão de Acadêmicos da Geração Y. IV Encontro de Ensino e Pesquisa em Administração e Contabilidade. Brasília, DF. Novembro de 2013.

PAVIONE, Caroline Stéffani Santos Nério. AVELINO, Bruna Camargos. FRANCISCO, José Roberto de Souza. Fatores que influenciam o Processo de Ensino-Aprendizagem sob a Perspectiva de Estudantes do Curso de Ciências Contábeis de uma Instituição de Ensino Superior Federal. REPeC, Brasília, v. 10, n. 2, art. 5, p. 196-219, abr./jun. 2016. 
RODRIGUES, Nayara Romão. PASSOS, Janduhy Camilo. Entre o Discurso e a Prática: o Olhar Docente e Discente sobre os Aspectos Pedagógicos em um curso de Ciências Contábeis. V EnEPQ. Salvador. 2015.

SANTOS, Morjane Armstrong. PIRES, Elaine Gonçalves. MACAMBIRA, Magno Oliveira. BRUNI, Adriano Leal. A construção do conhecimento sobre ensino e aprendizagem em contabilidade: um olhar sobre os congressos Usp e Anpcont no período de 2007 a 2011. Revista Evidenciação Contábil \& Finanças. João Pessoa, v.1, n. 1, p. 71-84, jan./jun. 2013.

SOUZA, Jocykleber Meireles de. MACÊDO, João Marcelo Alves. VIEIRA, Ana Cândida Ferreira. ANDRADE, Tabira de Souza. Atribuições de Causalidade para Explicar o Desempenho Acadêmico dos Estudantes de Ciências Contábeis e suas Reações Emocionais. X Congresso AnpCont. Ribeirão Preto, São Paulo. Junho de 2016.

VENDRUSCOLO, Maria Ivanice. BEHAR, Patrícia Alejandra. Educação e Pesquisa em Contabilidade: Estado da Arte do Congresso Usp de Controladoria e Contabilidade do Período de 2004 a 2012. Revista Ambiente Contábil - UFRN - Natal-RN. v. 6. n. 1, p. 83 98, jan./jun. 2014. 